\title{
The Role of the Cardioversion Defibrillator in Post Myocardial Infarction Sudden Cardiac Death: A Systematic Review of Clinical Trials and Observational Studies
}

\author{
Muhammad Haisum Maqsood ${ }^{1}$, Kinza Rubab ${ }^{1}$ \\ 1. Internal Medicine, King Edward Medical University / Mayo Hospital, Lahore, PAK
}

Corresponding author: Muhammad Haisum Maqsood, haisumbajwa@live.com

\begin{abstract}
Sudden cardiac death (SCD) accounts for approximately half of all the deaths attributed to cardiovascular disease in the United States. Survivors of an acute myocardial infarction (AMI) are at high risk of SCD, largely due to cardiac arrhythmias and severe left ventricular (LV) systolic dysfunction. The implantable cardioverter defibrillator (ICD) or automated implantable cardioverter defibrillator (AICD) is a device that is implantable inside the body, able to perform cardioversion, defibrillation, and (in modern versions) pacing of the heart. According to a study included in our review, patients who received an ICD contributed to an adjusted $44 \%$ reduction (hazard ratio [HR] 0.56, 95\% CI: $0.32-1.01 ; \mathrm{P}=0.053$ ) of all-cause mortality compared to those with a comparable baseline. Patients with an ICD implant three months after a myocardial infarction (MI) demonstrated a non-significantly higher mortality than patients who did not receive an ICD. The factors favoring ICD implantation were multiple MIs, increased resting heart rate, occurrence of non-sustained ventricular tachycardia, QRS duration $=120 \mathrm{~ms}$, syncope events, antiarrhythmic drug treatment (mostly Class III), and an index MI of more than one year. The likelihood of receiving an ICD diminished with the patient's age. Increased periodic repolarization dynamics were a significant predictor of mortality. It can be concluded that cardioverter defibrillators help reduce not only all-cause mortality but also sudden cardiac death. It is important to note that ICDs are only significant if implanted after a sufficient time-gap post-MI.
\end{abstract}

Received 02/15/2019

Review began 03/17/2019 Review ended 03/18/2019 Published 03/25/2019

() Copyright 2019

Maqsood et al. This is an open access article distributed under the terms of the Creative Commons Attribution License CC-BY 3.0., which permits unrestricted use, distribution, and reproduction in any medium, provided the original author and source are credited.
Categories: Cardiology, Internal Medicine, Public Health

Keywords: sudden cardiac death, cardioversion, defibrillator

\section{Introduction And Background \\ Description of the condition}

Sudden cardiac death (SCD) is a significant public health problem and accounts for approximately half of all the deaths attributed to cardiovascular disease in the United States [1]. The incidence of SCD ranges from 0.36 to 1.28 per 1,000 persons per year with approximately 400,000 deaths occurring annually in the United States alone [2-5]. It is most commonly associated with coronary artery disease and can be its initial manifestation or may occur in the period after an acute myocardial infarction [6]. Survivors of an acute myocardial infarction (AMI) are at high risk of SCD, largely due to cardiac arrhythmias and severe left ventricular (LV) systolic dysfunction [7]. Several studies have shown that about $5 \%$ to $10 \%$ of patients suffer SCD within the first year after the acute event [8-11]. Despite improvements in the treatment of coronary artery disease, more than half of all cardiovascular mortality is due to arrhythmic death [12]. Purkinje fibers, surviving but dysfunctional, are the main arrhythmogenic foci during the infarct evolution period. After one hour of ischemia, the Purkinje and surviving muscle fibers exhibit reduced resting potentials, decreased action potential amplitudes, and reduced upstroke velocities. The action potential duration, prolonged in muscle fibers, is shortened in Purkinje fibers, facilitating re-entry. Re-entry, flow of injury current, and abnormal automaticity (delayed after-depolarization) lead to arrhythmias [13].

\section{Description of the intervention}

Decreasing the rate of sudden cardiac death requires the identification and treatment of at-risk patients through evidence-based pharmacotherapy and interventional strategies aimed at primary and secondary prevention [14]. With the introduction of modern treatment, the incidence of SCD in myocardial infarction (MI) survivors may decline in parallel with coronary heart disease, especially in patients receiving optimal medical therapy (§-blockers, aspirin, statins, and angiotensin-converting enzyme [ACE] inhibitors) and revascularization [15-16]. Unfortunately, of all patients experiencing acute myocardial infarction (MI), usually in the form of ST-elevation MI, 25-35\% die of SCD before receiving medical attention, most often from ventricular fibrillation. Prognosis is better for patients who come to the hospital on time. Reperfusion therapy, better attained with primary percutaneous coronary intervention than with thrombolysis, has made a big difference in reducing the risk of SCD early and late after ST-elevation MI. In-hospital SCD due to ventricular tachyarrhythmias is manageable with preventive measures, drugs, or electrical cardioversion 
The implantable cardioverter defibrillator (ICD) or automated implantable cardioverter defibrillator (AICD) is a device implantable inside the body and able to perform cardioversion, defibrillation, and (in modern versions) pacing of the heart. ICD has the capability to rectify most life taking cardiac arrhythmias. The ICD is the first-line treatment and prophylactic therapy for patients at risk for sudden cardiac death due to ventricular fibrillation and ventricular tachycardia [17]. Since their introduction in the 1980s, the evidence supporting the use of implantable cardioverter defibrillators (ICDs) has steadily increased. Implantable cardioverter defibrillators are now the primary treatment modality for the prevention of SCD in high-risk patients [18-19]. Several professional societies have issued guidelines for ICD therapy for the primary prevention of SCD post-myocardial infarction (post-MI) [20-23].

\section{Why is it important to do this review?}

The absence of reviews that have assessed the role of cardioversion defibrillation, particularly in post-MI sudden cardiac death, has prompted us to evaluate the available evidence to establish the benefits and harms of the cardioverter defibrillator in such cases.

\section{Objective}

To evaluate the role of cardioversion defibrillation in post-MI sudden cardiac death.

\section{Review \\ Descriptive analyses/findings}

Effect on All-cause Mortality

According to a study included in our review, patients who received an ICD contributed to an adjusted $44 \%$ reduction (HR $0.56,95 \% \mathrm{CI}: 0.32-1.01 ; \mathrm{P}=0.053$ ) of all-cause mortality compared to those with comparable baseline characteristics but without an ICD. All-cause mortality of ICD recipients was significantly lower if the ICD was implanted later than 11 months after an acute MI $(\mathrm{P}=0.001)$ [24].

Effect on Sudden Cardiac Death

According to a study included in our review, ICD-therapy was associated with a reduction of SCD by $53.1 \%$ (P $<0.001)[25]$.

Decision Criteria

According to a study that we have included, patients with a left ventricular ejection fraction (LVEF) less than $30 \%$ had a 31-fold chance of receiving an ICD; patients with a 30\%-40\% LVEF had a six-fold chance, compared with the group having an LVEF greater than $40 \%$ to receive an ICD $(\mathrm{P}=0.001)$. Other factors favoring ICD implantation were multiple MIs, increased resting heart rate, the occurrence of non-sustained ventricular tachycardia, QRS complex duration = $120 \mathrm{~ms}$, syncope events, anti-arrhythmic drug treatment (mostly Class III), and an index MI of more than one year. The likelihood of receiving an ICD was reduced with older patient age [24].

Time from Index MI

The studies we have included found that the ICD implant three months after MI demonstrated a nonsignificantly higher mortality than patients who did not receive an ICD (HR 2.1, 95\% CI: 0.95-4.65; P = 0.068). A time period of 4-11 months after an MI showed that an ICD revealed a non-significant, moderate reduction of mortality (HR 0.72, 95\%, CI: 0.29-1.78; P = 0.469), and a subgroup of patients with ICD implantation more than 11 months after their index MI showed a significantly reduced mortality (HR 0.14 , 95\% CI: 0.03-0.56; $\mathrm{P}=0.006)$ [24].

Association with Periodic Repolarization Dynamics

Periodic repolarization dynamics (PRD) is a novel electrocardiographic phenomenon that refers to previously unknown oscillations of cardiac repolarization instability. Increased PRD was a significant predictor of mortality. Although increased PRD predicted SCD in conventionally treated patients (1.61 [1.23$2.11]$; $\mathrm{P}<0.001)$, it was predictive of non-sudden cardiac death (N-SCD) $(1.63$ [1.28-2.09]; P <0.001) in ICDtreated patients. ICD treatment substantially reduced mortality in the lowest three PRD quartiles by $53 \%(\mathrm{P}=$ 0.001). However, there was no effect in the highest PRD quartile (mortality increase by $29 \% ; \mathrm{P}=0.412 ; \mathrm{P}$ $<0.001$ for difference), because the reduction of N-SCD was compensated for by an increase of N-SCD [25]. 
Increased risk for SCD is predicted by age, LVEF equal to or less than $25 \%$, and non-revascularization [7].

Comparison with Revascularization

The results of a study included in this review showed that revascularization reduces the risk of SCD $(2.7 \%$ compared to $9.6 \%$ in non-revascularization). Revascularization may reduce the risk of SCD in post-MI patients with an LVEF $<35 \%$ on the basis of medical therapy [7].

\section{Discussion}

This systematic review has assessed the role of cardioversion defibrillation in post-MI sudden cardiac death. We included four studies and has revealed significant positive and negative aspects. As compared to the previous interventions, such as pharmacotherapy and revascularization, cardioversion defibrillation has a significant existence.

The increased risk for sudden cardiac death is predicted by age, LVEF equal to or less than $25 \%$, and nonrevascularization. Our systematic review signifies that the cardioverter defibrillator plays an important role in reducing all-cause mortality and sudden cardiac death. The reduction of SCD and mortality was more significant if an ICD was implanted after a longer time lapse from the index MI (particularly after 11 months). It also showed that the patients with an ejection fraction less than $40 \%$ had a greater probability of receiving an ICD than those with higher LVEF. Our study also involved periodic random depolarization, which is an important predictor of SCD in conventionally treated patients and that of negative SCD in ICDtreated patients.

The results of our systematic review are similar to the studies present in the literature. Our review endorses the renowned Multicenter Automatic Defibrillator Implantation Trial II (MADIT-II) that showed that prophylactic ICD reduces all-cause mortality by $31 \%$ in post-MI patients with systolic dysfunction (EF $\leqslant 30 \%$ ), compared to standard medical therapy [19]. However, the Defibrillator in Acute Myocardial Infarction Trial (DINAMIT) showed that prophylactic implantation of an ICD 6-40 days after acute MI in patients with left ventricular (LV) dysfunction (LVEF $\leqslant 35 \%$ ) and impaired autonomic function reduces arrhythmic deaths but does not improve all-cause mortality [26]. Similar to our results, the IRIS trial showed no overall survival benefit from starting implantable cardioverter defibrillator (ICD) therapy in the early weeks after an acute MI in patients with features that put them at increased risk for events [27]. The Multicenter Automatic Defibrillator Implantation Trial with Cardiac Resynchronization Therapy (MADITCRT) trial, conducted in the first decade of this century, stepped ahead and stated that among patients with heart failure (HF) with LVEF $\leqslant 30 \%$ and QRS complex duration $\geqslant 130 \mathrm{msec}$, placement of an ICD with cardiac resynchronization therapy reduces the rate of mortality or HF events, compared to ICD placement alone. This benefit was driven primarily by a reduction in HF events [19].

We revealed sufficient evidence regarding the impacts of the cardioverter defibrillator, particularly in postMI sudden cardiac death. A drawback of the available literature is that it fails to evaluate the complications associated with these implants systematically. The limitations of the included studies did not enable us to derive conclusive evidence about the adverse outcomes, if any.

\section{Conclusions}

It can be concluded that cardioverter defibrillators help reduce not only all-cause mortality but also sudden cardiac death. It is important to note that ICDs are only significant if implanted after a sufficient time-gap post-MI.

\section{Additional Information \\ Disclosures}

Conflicts of interest: In compliance with the ICMJE uniform disclosure form, all authors declare the following: Payment/services info: All authors have declared that no financial support was received from any organization for the submitted work. Financial relationships: All authors have declared that they have no financial relationships at present or within the previous three years with any organizations that might have an interest in the submitted work. Other relationships: All authors have declared that there are no other relationships or activities that could appear to have influenced the submitted work.

\section{References}

1. Myerburg RJ, Kessler KM, Castellanos A: Sudden cardiac death: epidemiology, transient risk, and intervention assessment. Ann Intern Med. 1993, 15:1187-1197.

2. Carveth SW, Olson D, Bechtel J: Emergency medical care system: Lincoln (Neb) mobile heart team . Arch Surg. 1974, 108:528-530.

3. Vertesi L: The paramedic ambulance: a Canadian experience. CMAJ. 1978, 8:25-29.

4. Myerburg RJ: Cardiac arrest and sudden cardiac death. Heart Disease: A Textbook of Cardiovascular Medicine. W. B. Saunders Publishing Co., 1992. 756-789. 
5. Engelstein ED: Sudden cardiac death. The Heart, Arteries and Veins. McGraw-Hill, 1081-1112; 1998. https://ci.nii.ac.jp/naid/10012167216/:

6. Sara JD, Eleid MF, Gulati R, et al.: Sudden cardiac death from the perspective of coronary artery disease . Mayo Clin Proc. 2014, 89:1685-1698.

7. Fan X, Hua W, Xu Y, et al.: Incidence and predictors of sudden cardiac death in patients with reduced left ventricular ejection fraction after myocardial infarction in an era of revascularisation. Heart. 2014, 100:1242-1249.

8. Ruberman, Weinblatt, Goldberg, et al.: Ventricular premature complexes and sudden death after myocardial infarction. Circulation. 1981, 64:297-305.

9. Multicenter Postinfarction Research Group: Risk stratification and survival after myocardial infarction . N Engl J Med. 1983, 309:331-336.

10. Bigger, Fleiss, Kleiger, et al.: The relationships among ventricular arrhythmias, left ventricular dysfunction, and mortality in the 2 years after myocardial infarction. Circulation. 1984, 69:250-258.

11. Mukharji J, Rude RE, Poole WK, et al.: Risk factors for sudden death after acute myocardial infarction: twoyear follow-up. Am J Cardiol. 1984, 54:31-36.

12. Zheng ZJ, Croft JB, Giles WH, et al.: Sudden cardiac death in the United States, 1989 to 1998 . Circulation. 2001, 104:2158-2163.

13. Clements-Jewery H, Hearse DJ, Curtis MJ: Phase 2 ventricular arrhythmias in acute myocardial infarction: a neglected target for therapeutic antiarrhythmic drug development and for safety pharmacology evaluation. Br J Pharmacol. 2005 Jul, 145:551-564.

14. Manolis AS: The clinical challenge of preventing sudden cardiac death immediately after acute ST-elevation myocardial infarction. Expert Rev Cardiovasc Ther. 2014, 12:1427-1437.

15. Huikuri HV, Tapanainen JM, Lindgren K, Raatikainen P, Mäkikallio TH, Juhani Airaksinen KE, Myerburg RJ: Prediction of sudden cardiac death after myocardial infarction in the beta-blocking era . J Am Coll Cardiol. 2003, 20:652-658.

16. Mäkikallio TH, Barthel P, Schneider R, et al.: Frequency of sudden cardiac death among acute myocardial infarction survivors with optimized medical and revascularization therapy. Am J Cardiol. 2006, 97:480-484.

17. Mirowski M, Reid PR, Mower MM, et al.: Termination of malignant ventricular arrhythmias with an implanted automatic defibrillator in human beings. N Engl J Med. 1980, 303:322-324.

18. Buxton AE, Lee KL, Fisher JD, et al.: A randomized study of the prevention of sudden death in patients with coronary artery disease. N Engl J Med. 1999, 341:1882-1890.

19. Moss AJ, Zareba W, Hall WJ, et al.: Prophylactic implantation of a defibrillator in patients with myocardial infarction and reduced ejection fraction. N Engl J Med. 2002, 346:877-883.

20. Zipes DP, Camm AJ, Borggrefe M, et al.: ACC/AHA/ESC 2006 guidelines for management of patients with ventricular arrhythmias and the prevention of sudden cardiac death. J Am Coll Cardiol. 2006, 48:247-346.

21. Epstein AE, DiMarco JP, Ellenbogen KA, et al.: ACC/AHA/HRS 2008 guidelines for device-based therapy of cardiac rhythm abnormalities: a report of the American College of Cardiology/American Heart Association Task Force on practice guidelines (writing committee to revise the ACC/AHA/NASPE 2002 guideline update for implantation of cardiac pacemakers and antiarrhythmia devices) developed in collaboration with the American Association for Thoracic Surgery and Society of Thoracic Surgeons. J Am Coll Cardiol. 2008, 51:162.

22. National Institute for Clinical Excellence. Implantable cardioverter defibrillators for arrhythmias . (2014). Accessed: November 28, 2018: https://www.nice.org.uk/guidance/ta314.

23. Tang AS, Ross H, Simpson CS, et al.: Canadian Cardiovascular Society/Canadian Heart Rhythm Society position paper on implantable cardioverter defibrillator use in Canada. Can J Cardiol. 2005, 21:11A-18A.

24. Völler H, Kamke W, Klein HU, et al.: Clinical practice of defibrillator implantation after myocardial infarction: impact of implant time: results from the PreSCD II Registry. Europace. 2010, 13:499-508.

25. Rizas KD, McNitt S, Hamm W, et al.: Prediction of sudden and non-sudden cardiac death in post-infarction patients with reduced left ventricular ejection fraction by periodic repolarization dynamics: MADIT-II substudy. Eur Heart J. 2017, 18:2110-2118.

26. Hohnloser SH, Kuck KH, Dorian P, et al.: Prophylactic use of an implantable cardioverter-defibrillator after acute myocardial infarction. N Engl J Med. 2004, 351:2481-2488.

27. Steinbeck G, Andresen D, Seidl K, et al.: Defibrillator implantation early after myocardial infarction. N Engl J Med. 2009, 361:1427-1436. 